\title{
Psychological care of the diabetic patient
}

\begin{abstract}
Diabetes Mellitus is a metabolic disease characterized by inability to assimilate glucose and chronic hyperglycemias. The World Health Organization distinguishes: Type 1 (T1DM), Type 2 (T2DM), Gestational Diabetes and secondary forms. All types need a complex, continuous and self-managed treatment that includes pharmacological therapy, regular measurements of the glycemic level, diet care and caution in daily activities. The experience we present is the result of collaboration between the Hospital Psychology Service, the Department of Endocrinology, Diabetology and Metabolism and the Department of Pediatrics of the S. Croce and Carle Hospital in Cuneo. The purpose of our intervention in diabetic patients during childhood and adult age is to promote awareness and adaptation to the disease, offering an early response in the event of suffering and psychological distress. In the article, we describe our working method and we briefly focus on the main problems that characterize paediatric and adult diabetic population
\end{abstract}

Keywords: diabetes, pediatrics, psychology, stress, compliance, psychological support
Volume 5 Issue 3 - 2018

\author{
Falco G,' Giordana C,', Cavalleri F,' Piacenza \\ A,' Magro G, ${ }^{2}$ Gianotti L, ${ }^{2}$ De Donno V, ${ }^{3}$ \\ Anfossi $M^{3}$ \\ 'Hospital Psychology Service, Presidio Health Directorate, Italy \\ ${ }^{2}$ Department of Endocrinology, Diabetology and Metabolism, S. \\ Croce and Carle Hospital, Italy \\ ${ }^{3}$ Department of Pediatrics, S. Croce and Carle Hospital, Italy
}

Correspondence: Falco G, Hospital Psychology Service,A.S.O. S. Croce and Carle (Cuneo), Presidium Health Directorate, Via Monte Zovetto, $n^{\circ} 18$ I2100, Cuneo (CN), Italy,

Email psicologia@ospedale.cuneo.it

Received: February 25, 2018 | Published: June 07, 2018

\section{Introduction}

Diabetes Mellitus is a metabolic disease characterized by the partial or total inability of the body to assimilate glucose, which causes an increase in blood glucose levels. ${ }^{1}$ The World Health Organization distinguishes some major forms of diabetes: Type 1 (T1DM), Type 2 (T2DM), Gestational Diabetes and secondary forms resulting from other diseases..$^{2-5}$ Although they are different for etiopathology and required treatment, all types of diabetes mellitus need a complex, continuous and largely self-managed treatment that includes pharmacological therapy, regular measurements of the glycemic level, diet care and caution in daily activities. ${ }^{6}$ All these issues shape social life, work and affect negatively patients' identity and body scheme. ${ }^{7}$ When the patient fails in accepting the pathology feels angry, sad and these emotions interfere with the management of the pathology. ${ }^{89}$ Therefore, psychological support should be part of the therapeutic process from the onset, in order to identify and treat risk factors, helping the patient in developing an adaptive approach, with positive outcomes on compliance and glyco-metabolic control. The experience we present is the result of collaboration between the Hospital Psychology Service, the Department of Endocrinology, Diabetology and Metabolism and the Department of Paediatrics of the S. Croce and Carle Hospital in Cuneo.

\section{Materials and method}

The aim of the psychological intervention is to promote awareness and adaptation to the disease, offering an early response in case of suffering and psychological distress. The modalities differ according to the age of the patient. For pediatric population, an integrated team has been active since 2007. The multi professional team is composed of pediatric diabetologists, specialized nurses, dietitians, psychologists and social workers. They propose different therapeutic sessions:

i. Family educational session in cases of new diagnosis to promote an appropriate communication of diagnosis and therapy

ii. Psychological Individual sessions for patients iii. Psychological session for parents

iv. group sessions for children / teenagers and their parents during follow up meetings called "Routard";

v. psychotherapies with patients and families with psychological or psychosocial disease that can affect negatively the therapeutic compliance;

vi. Day hospital counseling with children between 6 and 10, to promote self-management.

For adult population, a support activity has been progressively structured since 2012, in order to offer one or more individual sessions:

i. to newly diagnosed patients;

ii. to patients with long-lasting disease suffering from psychological problems or stressful events that interfere with the management of the disease;

iii. to diabetics hospitalized for glycemic decomposition or disease's complications.

For adult patients we use psychological interview. The consultation focuses on the current problem and offers a space to reflect and share disease-related experiences. The psychologist also shares information with the team and examines medical records to verify any previous psychiatric diagnoses. When necessary, we use grids to recognize psychological needs (the hospital team has created a special grid) and validated tests (HADS and TAS). In a number of cases, we use the approach EMDR to face up the stressful or traumatic impact of pathology's diagnosis and complications.

\section{Results and discussion}

Since 2014, a total of 302 patients have benefited from one or more psychological sessions. 78 of these are under the age of 18, while 224 are older. 134 are males, 168 are females. The most common problems, as already highlighted in our previous writings, ${ }^{10,11}$ are the following. 


\section{Limitations to everyday life}

Practical aspects of diabetes management that affect school, work and friendship, especially for young persons, diabetes is difficult to reconcile with daily and social life. They feel angry or sad for the need of therapy management during outdoor time and they suffer for the limitation of freedom.

\section{Difficulty in accepting the disease}

Cognitive or emotional refusal to suffer from a chronic illness that requires changes in lifestyle; negative experiences connected to the self-image as a sick person. Family difficulties: family members can negatively affect compliance if they don't provide support or if they have high conflict and/or psychopathologies.

\section{Psychological symptoms}

Anxiety and depression increased by the disease and interfering with the management of the therapies, especially among adolescents, we sometimes notice behavioral disorders.

\section{Stressful events}

Mourning, separation or accidents that precede the onset of diabetes and/or affect the progress of the disease.

\section{Psychiatric disorders}

Psychosis, substance addiction and eating disorders.

Our clinical experience has allowed us to detect a different approach depending on age. While for adults the main problem is the acceptance of the disease, minors seem to focus on social and educational limitations. In addition, an important aspect is the precocity of the diagnosis. When diabetes occurs in early childhood, there is no previous time to compare the present. Therefore, disease is assumed as a characteristic of itself and integrated with the selfconcept. Difficulties increase when the onset occurs in adolescence, because the changes imposed by the disease are added to the physical, social and psychological transformations, generating consequences on the identity. Finally, a diagnosis in adulthood disrupts established habits and routines, causing cognitive fatigue and generates concerns about future and complications. According to the age, the family context is involved in different degree. When the disease affects a child, parents can be an important protective factor that helps the young patient to accept the diagnosis and to manage the therapy and diet changes. When they struggle to accept the illness of the child, they transmit anxious and insecure coping skills. For these reasons, the care of a minor with DM must always include a complementary intervention on the family unit.

\section{Conclusion}

Our experience suggests the importance of psychoneuroendocrinological care of the diabetic patiet. ${ }^{12,13,14}$ The continuous collaboration between the psychologist and the diabetic team prevents, recognizes and treats psychological suffering, with positive consequences on the quality of life, on therapeutic compliance and outcomes.

\section{Acknowledgements}

We thank all doctors and nurses of the Department of Endocrinology, Diabetology and Metabolism ${ }^{1}$ and the Department of Pediatrics ${ }^{2}$ of S. Croce and Carle Hospital in Cuneo. We also thank AMD (Associazione Medici Diabetologi) for funding the psychological support and research activities in the period between October 2015 and October 2016.

\section{Conflict of interest}

The author declares not to have conflicts of interest.

\section{References}

1. Holt T, Kumar S. ABC of Diabetes. $6^{\text {th }}$ edn. Oxford: Wiley-Blackwell; 2013.

2. Shaw JE, Sicree RA, Zimmet PZ. Global estimates of the prevalence of diabetes for 2010 and 2030. Diabetes Res Clin Pract. 2010;87 (1):4-14.

3. Groop L. Pathogenesis of type 2 diabetes: The relative contribution of insulin resistance and impaired insulin secretion. Int J Clin Pract. 2000;113:3-13.

4. Kassi E, Panagiota Pervanidou P, Kaltsas G, et al. Metabolic syndrome: definitions and controversies. BMC Med.2011;9:48.

5. Van Belle TL, Coppieters KT, Von Herrath MG. Type 1 diabetes: etiology, immunology, and therapeutic strategies. Physiol Rev. 2011;91(1):79-118.

6. Miselli V. Il problema dell'adesione alla terapia in una malattia cronica come il diabete. G It Diabetol Metab. 2011;31:121-124.

7. DAWN Italia (Diabetes Attitudes Wishes \& Needs). Ministero della SaluteInternational Diabetes Federation-Associazione Diabete Italia. 2007.

8. Gianotti L, Falco G, De Bellis R. Stress, sindrome metabolica e diabete mellito. In Bottaccioli F, Psiconeuroendocrinologia e scienza della cura integrata. Edra: Milano; 2017.

9. Stankovic Z, Jašovic-Gašic M, Lecic-Toševski D. Psychological problems in patients with type 2 diabetes-Clinical considerations. Vojnosanit Pregl. 2013;70(12):1138-1144.

10. Falco G, Cavalleri F, Magro G, et al. Gli aspetti psicologici del diabete mellito in pediatria e nell'età adulta. Poster for the XX National Congress AMD: Genova; 2015. p. 13-16.

11. Falco G, Cavalleri F, Magro G, et al. The psychological aspects of diabetes mellitus in pediatrics and adulthood. The Journal of AMD. 2015;18:183187.

12. Bottaccioli F. Psiconeuroimmunologia. Red Edizioni: Como; 2001.

13. Bottaccioli F. Psiconeuroendocrinoimmunologia. The scientific foundations of the mind-body relationships. The rational basis of integrated medicine. Red Edizioni: Milano; 2005.

14. Gianotti L, Falco G, Pinta C, et al. The contribution of the psycho-neuroendocrine-immunology to the treatment of chronic disease: the example of diabetes mellitus. Figure Emergenti; 2016. 